\title{
ADVANCES IN COASTAL DISASTERS RISK MANAGEMENT - LESSONS FROM THE 2011 TOHOKU TSUNAMI
}

\author{
Sebastiaan N. Jonkman ${ }^{1}$, Tomohiro Yasuda ${ }^{2}$, V. Tsimopoulou ${ }^{3}$, H. Kawai ${ }^{4}$ and F. Kato ${ }^{5}$ \\ The earthquake and tsunami of March 2011 led to death and destruction in coastal areas in Japan. A seminar was \\ held in June 2012 for Japanese and Dutch coastal researchers to discuss lessons for the management of the risks in \\ coastal areas associated with tsunamis, typhoons and storm surges. The seminar has highlighted important practical \\ and theoretical issues in coastal protection, risk and emergency management, and climate change and sea level rise \\ research that are of importance for the Netherlands and Japan and other coastal regions. The performance of the \\ system during historical events gives important lessons for the (re)design of resilient coastal protection systems in the \\ future. It has also been discussed how risk assessments can be utilized to determine how an effective combination of \\ prevention, land use planning and emergency management can be implemented to minimize future risks in the \\ coastal zone.
}

Keywords: 2011 Tohoku tsunami; coastal disasters; risk management; coastal structures; resilience.

\section{BACKGROUND AND OBJECTIVES}

\section{General}

The earthquake and tsunami of March 2011 led to death and destruction in coastal areas in Japan. After the several tsunami investigations have focused on the effects of the earthquake and the tsunami, the performance of coastal defences and the preferred strategies and measures for rebuilding the coastal areas and managing the risk has been discussed. In addition to tsunami hazards, many of the densely populated coastal areas in Japan (e.g. the Tokyo Bay area) are prone to flooding due to coastal storms and typhoons.

The threat of various coastal hazards (storms, floods) is also very prominent in the Netherlands as large parts of the country are below sea level. Past disasters in the Netherlands (e.g. the 1953 storm surge disaster) and abroad (e.g. hurricane Katrina in New Orleans and the Tohoku tsunami in Japan) provide important opportunities to learn more about the devastating effects of disasters and possible strategies to minimize these coastal risks. It is therefore important to analyze, evaluate and discuss the lessons from such disastrous events.

On June 7 and 8, 2012 a seminar has been organized in Sendai, Japan to exchange information between Dutch and Japanese researchers to improve the methods for assessing, managing and mitigating coastal risks. In the days before the seminar, field visits have been organized to the coastal and river flood protection in Tokyo (June 4) and coastal areas affected by the March 2011 tsunami (June 5 and 6). The following key questions have been addressed:

- What were the causes and effects of the March 2011 tsunami?

- What was the performance of the coastal protection system and which lessons can be learned for design and coastal management?

- Which strategies will be and can be used for reducing and managing the risks in coastal areas of Japan and the Netherlands?

The seminar has not only focused on engineering measures to prevent such disasters by means of coastal defences (e.g. dikes, levees, breakwaters and seawalls), but also on land use planning and emergency management. It has also been addressed how future developments, such as climate change and economic and population growth in coastal areas can be taken into consideration in the risk management strategy for coastal areas.

\footnotetext{
${ }^{1}$ Delft University, Section of Hydraulic Engineering, Stevinweg 1, 2628 CN, Delft, the Netherlands

${ }^{2}$ Kyoto University, Disaster Prevention Research Inst.(DPRI), Japan.

${ }^{3}$ Delft University and HKV Consultants, Delft, the Netherlands

${ }_{5}^{4}$ Port and Airport Research Institute, Yokosuka, Japan.

${ }^{5}$ National Institute for Land and Infrastructure Management (NILIM), Tsukuba, Japan
} 


\section{Coastal management in Japan and the Netherlands}

The seminar and the contents of this paper focus mainly on lessons coastal flood management for the Netherlands and Japan (see also Jonkman et al., 2006). Yet findings will be presented in an international context.

There are similarities and differences between the coastal systems and threats in the Netherlands and Japan. The coastline of the Netherlands is about $450 \mathrm{~km}$ long and coastal defences consist of sand dunes, coastal dikes and barriers. These protect densely populated and valuable in the west of the country. The main threats are storm surges from extra-tropical storms and coastal erosion. The Japanese coastline is much longer, almost $35,000 \mathrm{~km}$, and about $25 \%$ of the coastline is protected by means of hard structures such breakwaters, dikes and gates. These provide coastal protection against tsunamis and typhoons. Most of the densely populated areas, such as Tokyo and Osaka, are located along the coast.

Despite the differences in the size of the country and coastal protection and threats there are various similarities. In both countries, the coastal (protection) system is essential for reducing and managing the risks in densely populated urban areas along the coasts. Despite the current economic stagnation in both Japan and the Netherlands, the values and populations in coastal areas are still growing, leading to an increase of potential impacts and risks if no measures are taken. Both countries have to cope with aging coastal infrastructure, as many of these systems have been constructed in the 1960's and 1970's and are not sufficient for the current standards. For the future, sea level rise and climate change could lead to increases of loads on coastal defences. It is therefore essential to exchange and develop the state-of-theart approaches for assessing and managing coastal risks and systems.

The structure of the remainder of this paper is as follows. The second section presents some main characteristics of the tsunami disaster and observations from field visits. The following sections discuss the workshop findings for various themes and recommendations for coastal risk management.

\section{TOHOKU TSUNAMI CHARACTERISTICS AND FIELD OBSERVATIONS}

The scale of the disaster was immense. Almost $600 \mathrm{~km}$ of coastline has been affected by the tsunami, 15,850 people were killed and more than 3,200 people are still missing. The economic losses were between 16 and 25 trillion Yen (between 160 and 250 billion Euro). In an extensive effort Japanese scientists have recorded tsunami inundation and run-up heights, see figure 1 . In the limited time available within this project no complete assessment of the impacts was possible. Yet, some observations that are relevant for coastal risk management are summarized below. 


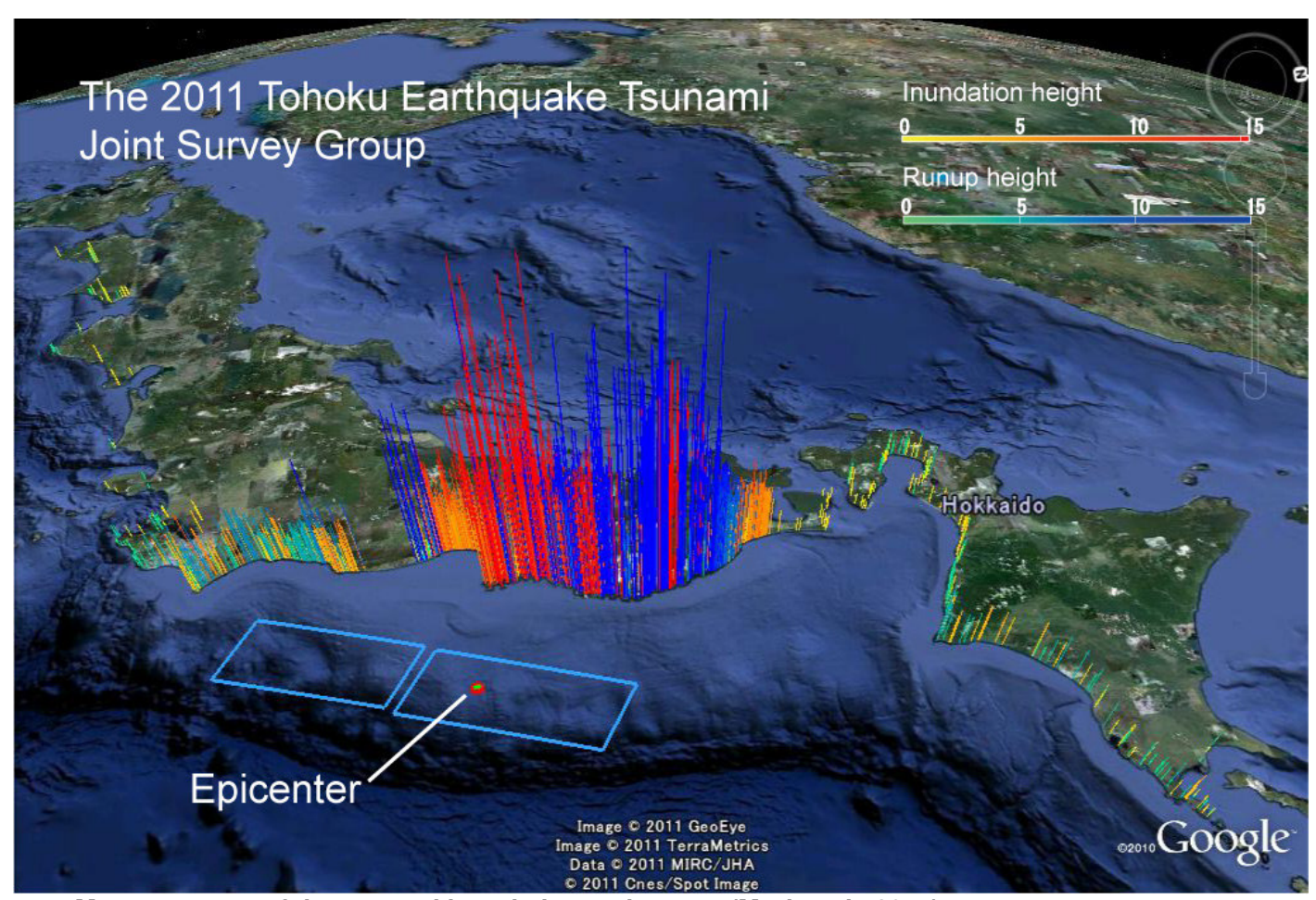

Figure 1: Measurements of the tsunami inundation and run-up (Mori et al., 2011).

The event has proven that extreme and rare events can happen and that their magnitude can exceed historical records. In many affected locations tsunami heights were higher than ever recorded in history. The consequences for such extreme events are very large (see numbers presented earlier). The disaster also gives insight in the composition of the damage. Firstly, there is the extensive loss of life and direct damage to houses, infrastructure, vehicles and other objects. A very significant component that is not addressed in most existing flood and disaster loss models is the indirect losses from business and damages to the national and even global economy. Finally, there are the high costs of rehabilitation and reconstruction.

The event gave empirical support for possible tsunami heights and for on-land propagation of the tsunami wave. By using video observations, flood simulation models for such tsunami and flood events can be calibrated and improved. These models can be utilized to evaluate several protection measures

The field observations give empirical support for the tsunami loading on structures such as breakwaters, coastal dikes and tsunami walls, and the resistance and failure modes of these structures in extreme conditions. More specifically, phenomena such as scouring, wave reflection and impulsive loads as a function of time can be better understood by analyzing the observations. Even $10 \mathrm{~m}$ high solid concrete walls failed due to the enormous impact. As part of the protection system floodgates were in place at locations where rivers flowed into the ocean (See Fig. 2). Not all floodgates could be closed during the disaster, due to the earthquake and the limited time available before arrival of the tsunami wave. Some of the floodgates were also structurally damaged due to the event. 


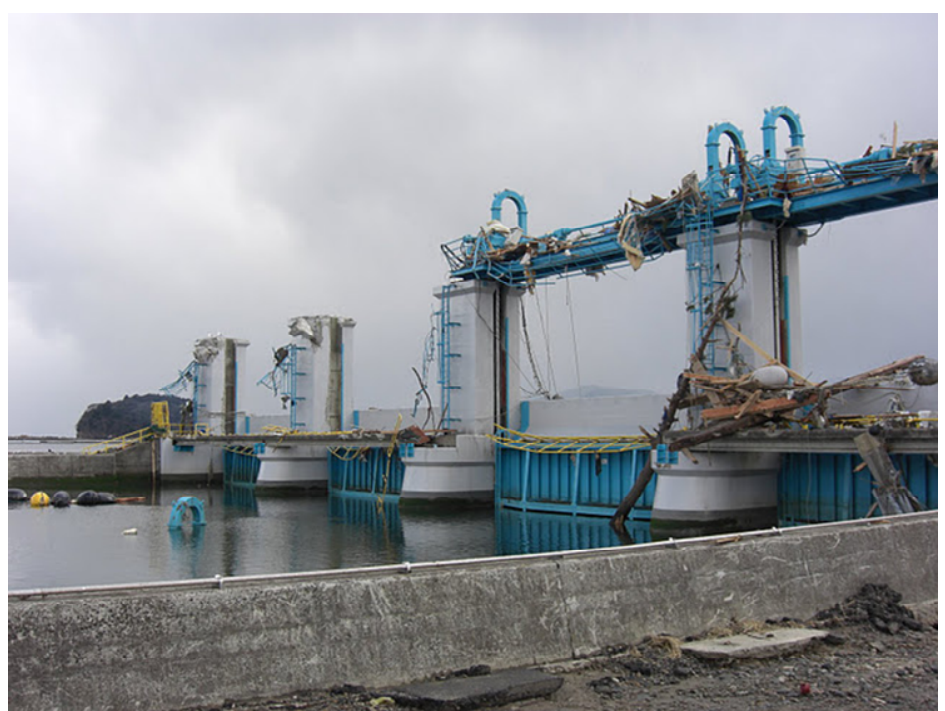

Figure 2: Damaged floodgate at Minamisanriku

A through analysis of flood and impact patterns with some support of numerical simulation can also reveal in which conditions the coastal defences have contributed to the reduction of the hazard and / or consequences. For example, for the town of Kamaishi it is expected that the presence of the breakwater in the bay mouth has reduced tsunami flood levels in the town by $30 \%$ to $40 \%$.

Positive and negative experiences with evacuation were reported. Many people were saved, but also many people did not survive. A careful evaluation of the events can give more insight in effective emergency management strategies. The outcomes should influence future emergency planning in Japan, but also other parts of the world.

In the coastal areas of Japan a risk reduction is in place that relies on various "layers" of protection (protection, land use planning and emergency management). This tragic event is also an opportunity to learn how such a multiple layered system performs under extreme conditions. From the field visits and information from experts, it appeared that the level of damage was dependent on the (combined) performance of coastal protection, previous land use planning policies and possibilities to take shelter in safe structure or high ground.

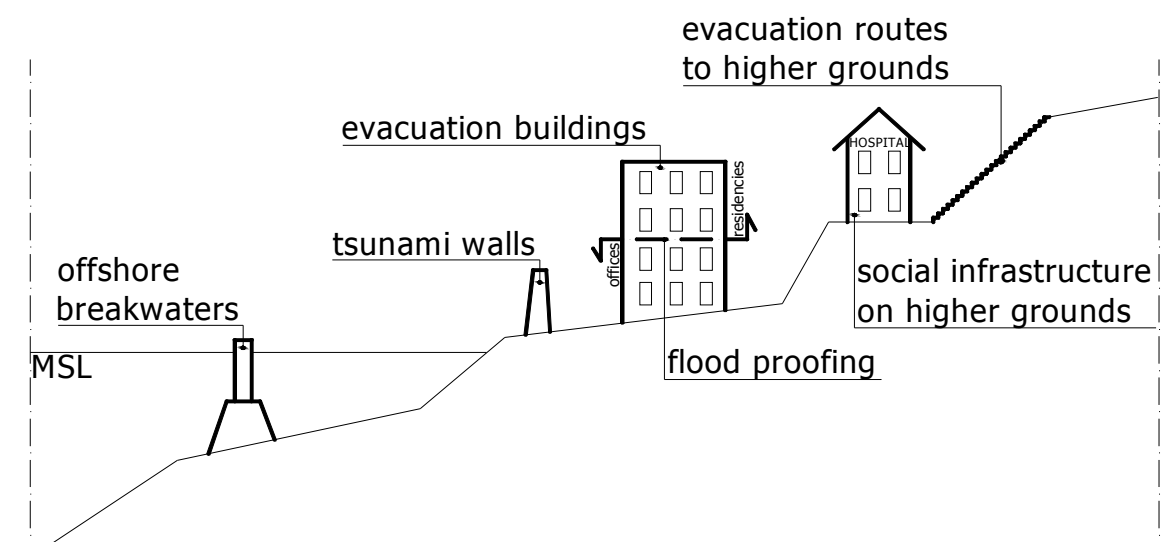

Figure 3: Typical measures for tsunami risk reduction along the Rias type coast (bays) ( Tsimopoulou, 2012).

\section{RELEVANT FINDINGS FOR COASTAL RISK MANAGEMENT}

The performance and design of coastal protection systems

The March 2011 resulted in a severe overloading of the coastal defences (dikes, seawalls) and failure in various locations. The behaviour of the coastal protection under such conditions is not yet well-understood and field observations from the disaster and follow-up experiments are important sources of new knowledge. 
(1) Wave force acting on the seawall
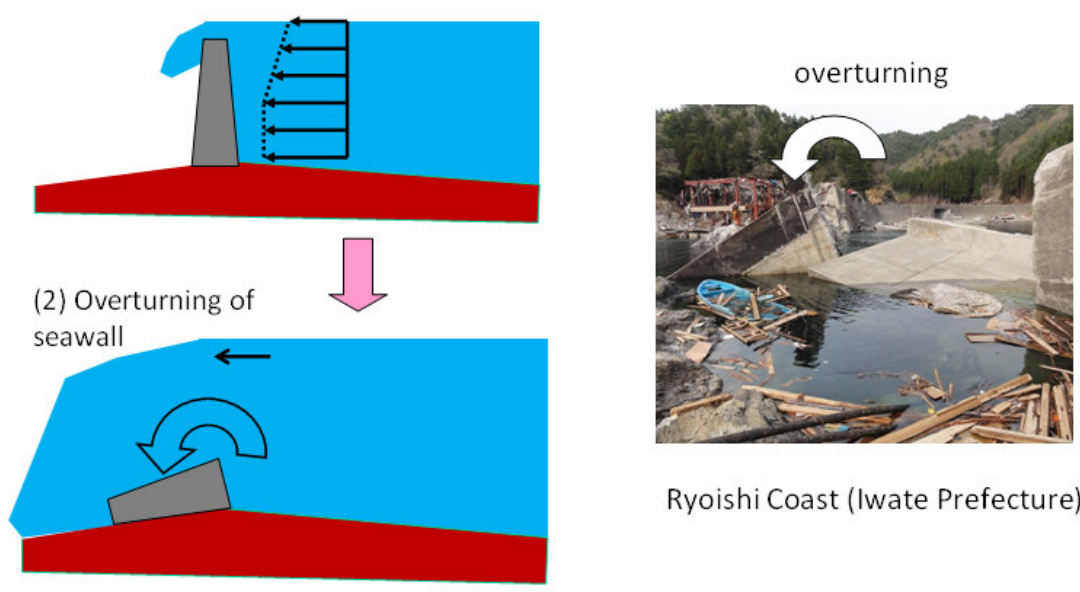

Ryoishi Coast (Iwate Prefecture)

Figure 4: Overturning of seawalls during the March 2011 tsunami event (Presentation F. Kato, this seminar).

Both in the Netherlands and Japan, it has been discussed how coastal protection should perform if load is exceeded the design level. Related concepts such as resilience (also applied in New Orleans after hurricane Katrina), resilient structures (Japan) and overflow and overtopping resistant deltadikes (the Netherlands) are under discussion. An important research question is how such systems can be safely designed.

In the current Japanese guidelines a concept is proposed in which a structure is designed to perform safely until the design load (level 1) and a higher (potential maximum) level of loading (level 2 ) for which some damage to the structure is allowed. From a risk management perspective (also see the next section) it is important to define the rationale for designing for certain structure behaviour during overloading. It should be defined and investigated if the behaviour of the overloaded structure contributes to the reduction of damage, life loss, improvement of evacuation or other purposes.

In the Netherlands and Japan, challenges exist with respect to managing and investing in the aging coastal infrastructure, also given possible future changes, such as sea level rise. A rational approach is to come to an effective asset management and investment program given the limitations in budget. Research can contribute to the development of new and better approaches for optimizing and prioritizing for management of coastal infrastructure.

\section{Multiple layers of safety and risk management}

Both in the Netherlands and Japan, it is under discussion how multiple levels or layers of protection (coastal defences, land use planning and emergency management) can contribute to a reduction of risks from storm surges and tsunamis (see also Fig. 3). Related concepts have been developed in other parts of the world, e.g. "multiple lines of defence" in New Orleans. Information and experiences from the March 2011 tsunami can be used to a) evaluate the performance of such a multilayered risk reduction system; b) to develop effective strategies to reduce future risks. At this moment, discussions are ongoing on appropriate redevelopment and risk reduction strategies for the areas affected by the tsunami. The figure below gives an example of a proposed strategy for the Sendai area.

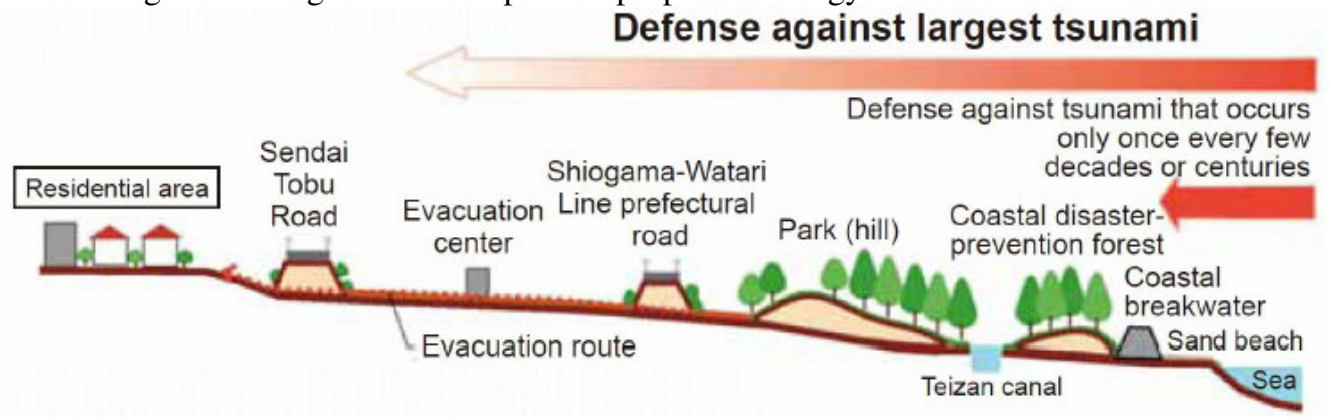

Figure 5: One of the proposed strategies for the future protection on the Sendai coastal area (Presentation S. Koshimura, this seminar). 
The bases for deciding on investments in coastal protection and other layers of protection differ between the Netherlands and Japan. Decision making in Japan on investments in the system is largely based on local political decision-making and consensus. In the Netherlands "rationalized" approaches such as Cost Benefit Analysis, and criteria for acceptable risk to life are used to support decision making. As a scientific case study it is recommended to elaborate a case study for an area in Japan in which Dutch concepts are applied.

\section{Emergency management}

One of the main questions that was discussed is how emergency managers can plan for extreme events. The evidence from the disaster in Japan highlighted the relationship between emergency management, land use planning and coastal protection. In some of the presented examples, the ability for people to escape was heavily dependent on the level of development in tsunami prone areas and the preparation in advance. About $60 \%$ people evacuated directly after the earthquake and did not wait for another early warning. This relatively high percentage can be associated with the high level of preparedness (by means of drills and exercises) and the high frequency of earthquakes in Japan.

The field evidence from the Sendai plain and analyses for deep polders in the Netherlands, shows that for these areas without natural high grounds nearby vertical evacuation should be the preferred strategy. However the question remains how high and strong these buildings have to be, and if people can reach this destination. Despite planning assumes people to evacuate by walking, it is shown that many (about 60\%) people uses cars which decreases effectiveness of evacuation because of traffic jams. The events and lessons from the 2011 tsunami provide an important basis for better understanding warning, response and evacuation effectiveness in extreme conditions. Criteria have to be developed that can be used to answer the question when emergency planning is successful. Emergency planners should take into consideration the fact that unforeseen events happen and that some people will not evacuate. Further joint study of the available data by Dutch and Japanese scientists is recommended, and the links with other extreme events (e.g. the 2010 tsunami in Chile) and the factors that can influence evacuation effectiveness.

\section{ACKNOWLEDGEMENTS}

The research has been supported by JSPS (the Japan Society for the Promotion of Science) and NWO (Netherlands Organization for Scientific Research) and these organizations are gratefully acknowledged for this support.

\section{REFERENCES}

Jonkman S.N., Kato F., Vrijling J.K. (2005) A comparison of flood risk assessment practices in the Netherlands and Japan, in: J. McKee Smith (ed.) Proc. Of the $29^{\text {th }}$ int. conf on Coastal Engineering ICCE2004, Lisbon, Portugal, pp. 3049-3060

Mori N., Takahashi T., Yasuda T., Yanagisawa H. (2011) Survey of the Tohoku earthquake tsunami inundation and run-up. Geophysical Research Letters Vol. 38, L00G14, 6p, doi:10.1029/2011GL0492102011.

Tsimopoulou V. (editor) (2012) The Great Eastern Japan Earthquake and Tsunami - Facts and implications for flood risk management. HKV Lijn in Water en TU Delft report. 